\title{
Bigadiç Kolemanitin Tozaltı Kaynak Toz Bileşeni Olarak Kullanılabilirliği
}

\author{
Mustafa KAPTANOĞLU* (10 \\ Fırat Üniversitesi, Mühendislik Fakültesi, Metalurji ve Malzeme Mühendisliği, Elazığ, Türkiye
}

Geliş / Received: 20/11/2018, Kabul / Accepted: 08/04/2019

\begin{abstract}
Öz
Bu çalışmada, tozaltı kaynak toz bileşeni olarak kullanma amaçlı, Eti Maden Bigadiç işletmesinden temin edilen kolemanitin $\left(2 \mathrm{CaO} .3 \mathrm{~B}_{2} \mathrm{O}_{3} .5 \mathrm{H}_{2} \mathrm{O}\right)$, kaynak işlemi sonrasında elde edilen kaynak metalinin tipik özelliklerine etkisi araştırılmıştır. Yapılan ön testler neticesinde, \% 0-4 oranında kolemanitin azami toz bünyesinde kullanılabilir olduğu tespit edilmiştir. Hazırlanan toz karışımlarında, oksitli ve florürlü bileşikler, eser miktarlarda ferroalaşımlar ve 4 farklı yüzdelik oranda kolemanit toz karışımı içerisinde kullanılarak, kaynak testlerinde kullanıma uygun kaynak tozları elde edilmiştir. Yapılan kaynak testleri neticesinde; elde edilen kaynak metalinden alınan numuneler, metalografik olarak hazırlanmış ve sırasıyla mikroyapı, sertlik ve aşınma testlerine tabi tutularak kolemanitin etkisi araştırılmıştır. Çalışma sonunda artan oranlarda kolemanitin kaynak tozu bünyesinde kullanımı ile mikro yapılardaki tane yapısının kısmi olarak kabalaştığı, sertliğin kısmi olarak düştüğü ve aşınma direncinin de kısmi olarak azaldığı tespit edilmiştir. Ayrıca, toz karışımı içerisinde artan miktarlarda kolemanit kullanımı ile, kaynak sonrası oluşan cürufların kendiliğinden kalkmasında gecikmeler olduğu ve kaynak tozlarının (flaks) bağ yapısının güçlendiği tespit edilmiştir.
\end{abstract}

Anahtar Kelimeler: toz altı kaynak tekniği, Bigadiç kolemanit, kaynak metali, kaynak tozu.

\section{Usability of Bigadic Colemanite as Submerged Arc Welding Powder Component}

\begin{abstract}
In this study, effect of colemanite $\left(2 \mathrm{CaO} .3 \mathrm{~B}_{2} \mathrm{O}_{3} .5 \mathrm{H}_{2} \mathrm{O}\right)$ obtained from the Eti Maden Bigadic company, which was prepared for the aim of submerged arc welding powder component, to the typical properties of the weld metal obtained after welding process has been investigated. As a result of the preliminary tests, colemanite in the range of 0-4\% can be used in welding powder mixture were determined. In welding powder mixtures prepared, oxidized and fluoride compounds, trace amounts of ferroalloys and 4 different percentages of colemanite were used to obtain welding powders suitable for welding tests. After the welding tests; samples obtained from the welded metal were prepared metallographically and subjected to microstructure, hardness and abrasion tests respectively and the effect of colemanite on welding metal was investigated. At the end of the study, it was determined that the grain structure in the microstructures was partially became coarsen, the hardness values decreased partially and the wear losses increased partially by the use of increasing amounts of colemanite in welding powder. In addition, with the use of increasing amounts of colemanite in powder mixtures, there were delays in terms of self-removal of slags occurred after welding processes and had more strength bond structures of welding powders (flux) were obtained.
\end{abstract}

Keywords: submerged arc welding technique, Bigadic colemanite, welding metal, welding powder.

\section{Giriş}

Toz altı kaynağı, tükenen elektrot (kaynak teli) ve iş parçası arasında meydana gelen 1sının avantajından yararlanarak gerçekleştirilen bir ark kaynak yöntemidir. Ark bölgesi, kaynak tozu, kısmi olarak ergiyen cüruf tabakası ve kaynak dikişi tarafindan korunur. Toz altı kaynak tekniğinde, uygulanan elektrik enerjisi, meydana gelen ark sayesinde, ergiyen metalden ve kısmi olarak ergiyen cüruftan geçerek kaynak banyosuna ulaşır. Ark nedeniyle oluşan 1s1, elektrotu, kaynak tozunu ve iş parçasını ergiterek kaynak banyosunun oluşmasını sağlar. Kaynak işleminde koruyucu roldeki kaynak tozları, kaynak banyosu ile de etkileşime geçerek kaynak metalinin deoksidasyonuna da katkı sağlar (Külahlı, 1988). 
Toz altı kaynak toz bileşenlerinin görevleri birbirinden farklı olup, tüm bileșenler farklı bir ihtiyaca binayen karışıma katılmaktadır. Silisyum dioksit $\left(\mathrm{SiO}_{2}\right)$; asidik özelliğe sahip olup, viskozite ve ergime sicaklığının ayarlanmasina yardımcı olmaktadır. Alüminyum oksit $\left(\mathrm{Al}_{2} \mathrm{O}_{3}\right)$; doğal bileşen olup, cüruf oluşumunu sağlayarak, kaynak yapılabilirliği kolaylaştırmaktadır. Ayrıca; viskozite ve ergime sicaklığının ayarlanmasına yardımcı olmakta ve yüksek akımlarda arkın kararlılığını sağlamaktadır. Titanyum dioksit $\left(\mathrm{TiO}_{2}\right)$; asidik özelliğe sahip olup, cüruf oluşumunu başlatıcı bileşiktir. Cürufun kolayca kalkmasına yardımcı olmaktadır. Kalsiyum oksit $(\mathrm{CaO})$; bazik özelliğe sahip olup, cürufun viskozitesinin ayarlanmasına yardımcı olup, kaynak metalinde oksijen miktarını azaltmaktadır. Kalsiyum florür $\left(\mathrm{CaF}_{2}\right)$; bazik özelliğe sahip olup, cürufun akışkanlığını iyileştirmekte ve flor gazının oluşumunu sağlayarak ve kısmi buhar basıncını düşürerek kaynak metalindeki hidrojen miktarını azaltmaktadır. Mangan oksit (MnO); bazik özelliğe sahip olup, kaynak metalinin şeklini geliştirerek, cürufun ergime sicaklığ 1 ve viskozitesinin ayarlanmasında etkilidir. Magnezyum oksit $(\mathrm{MgO})$; bazik özelliğe sahip olup, ergimiş cürufun bazikliğini arttırmakta ve hidrojenin kaynak metalinden cürufa doğru ilerlemesini sağlamaktadır. Potasyum oksit $\left(\mathrm{K}_{2} \mathrm{O}\right)$, sodyum oksit $\left(\mathrm{Na}_{2} \mathrm{O}\right)$ ve lityum oksit $\left(\mathrm{Li}_{2} \mathrm{O}\right)$; bu bileşikler arkın kararlı olarak devam etmesinde önemli rol oynamaktadır (Davis, 1993).

Kolemanitin kimyasal formülü $2 \mathrm{CaO} .3 \mathrm{~B}_{2} \mathrm{O}_{3} .5 \mathrm{H}_{2} \mathrm{O}$ ' tür. Kolemanit bor mineralleri arasında en yaygın olarak bulunanlardan biridir. Killer içinde, cevher boşluklarında iri, parlak, saydam kristaller halinde görülür. Mono klinik kristallenme gösteren Kolemanitin sertliği Mohs sertlik sınıflandırmasına göre 4-4,5 özgül ağırlığı ise $2,42 \mathrm{gr} / \mathrm{cm}^{\prime}$ ' tür. $\mathrm{B}_{2} \mathrm{O}_{3}$ içeriği \% $\quad 27-42$ aralığındadır. Kolemanit cam elyaf üretiminde (tekstil tipi cam elyaf), seramik ve emaye sır formülasyonları içerisinde ve metalurji sanayiinde flaks olarak da kullanılmaktadır. Ayrıca; demir-çelik sektöründe tozlaşan cürufa ilave edilerek kompakt yapıda cüruf elde etmek amaciyla da kullanılmaktadır. (Eti Maden, 2018; Demir vd., 2017).

Sivrikaya ve Arol (2012), organik bağlayıcılar ile bağlanan pişmiş ve önceden 1sitılmış peletlerde bulunan yetersiz mukavemeti gidermek için kolemanitin bağlayıcı olarak etkisini araştırmışlardır. Çalışma sonunda tek başına organik bağlayıcı ya da tek başına kolemanit kullanımının bağ mukavemetine pozitif bir etkisinin olmadığını gözlemlediklerini belirtmişlerdir. Öte yandan; organik bağlayıcı ile birlikte kullanılan kolemanitin, pelet mukavemetine katk1 sağladığını belirtmişlerdir. Eskibalcı ve Özkan (2012), Türkiye Eti Maden A.Ş. Bigadiç Maden İşletmesinden temin edilen üleksit ve kolemaniti elektrostatik olarak ayırmak için, mikro dalga enerjisinin etkisini incelemişlerdir. Çalışma sonunda; aralarındaki elektrostatik özellik farkından yararlanarak çeşitli ısıl işlemlerle üleksit ve kolemanitin birbirinden ayrilabileceğini ortaya koyan sonuçlar elde ettiklerini belirtmişlerdir. Rüşen vd. (2012), \% 0 ile 6 oranlarında kolemanit ekleyerek bakır matının cürufunda oluşan bakır kayıplarının en aza indirgenmesi üzerine araştırma yapmışlardır. Çalışma sonunda; kolemanit miktarının artmasıyla \% 1,5 olan bakır kayıplarının \% 0,4 seviyesine düştügünü belirtmişlerdir. Gül vd. (2006), flotasyon ve karıştırma yoluyla Kestelek Bor Maden işletmesinde oluşan kolemanit içeren atık suların zenginleştirilmesi üzerine çalışmışlardır. Çalışma sonunda; atıktaki $\mathrm{B}_{2} \mathrm{O}_{3}$ miktarında ciddi miktarda artış sağlandığ 1 ve $\%$ 68,4 geri kazanımla $\% \quad 44,5 \quad \mathrm{~B}_{2} \mathrm{O}_{3} \quad$ içeren bir konsantrasyon elde edildiği belirtilmiştir. Bideci ve Bideci (2018), öğütülmüş kolemanit ilavesinin inşaat sektöründeki çimento harç 
özelliklerine etkisi araştırmıştır. $\mathrm{Bu}$ doğrultuda; farklı yüzdelik oranlarda harç karışımları oluşturarak özgül ağırlık, özgül yüzey, priz başlama ve sona erme süreleri tayini, kıvam ve genleşme deneylerinin yapılması ve harç numunelerin basınç dayanımı gibi parametrelerde bu karışımları testlere ve ölçümlere tabi tutmuşlardır. Çalışma sonunda; artan kolemanit yüzdesine bağlı olarak pozitif sonuçlar elde edildiği ve kolemanitin standartlara uygun ikame harç malzemesi olarak kullanılabilirliğini belirtmişlerdir. Başar vd. (2018), farklı oranlarda kolemanit içeren balatalar üreterek, ürettikleri balataların sürtünme ve aşınma karakteristiklerini araştırmışlardır. Gerçekleştirilen çalışma sonunda; \% 4 kolemanit takviyeli balataların, sürtünme katsayısı bakımından en verimli sonuçları verdiği belirtilmiştir. Ayrıca; üretimi başarı ile tamamlanan bu balataların standartlara uygun olduğu ve kolemanit ilavesinin, balataların frenleme performansına doğrudan etki ettiği ifade edilmiştir. Çiftçi ve Atik (2015), Eti Maden İşletmeleri Bigadiç Bor İşletmesi artık ürünlerinin değerlendirme olanaklarını araştırmışlardır. $\mathrm{Bu}$ kapsamda; atıkların bünyesinde bulunan kil minerallerinin giderimini sağlayarak, atığın tenörünü yükseltmeyi hedeflemişlerdir. Bu doğrultuda; atığa mekanik aşındırma-dağıtma testleri ve 1S1 ile dağıtma testleri uygulamışlardır. Çalışma sonunda; \% 45,57 $\mathrm{B}_{2} \mathrm{O}_{3}$ tenörlü bir konsantre ürün olan kolemanitin, tenör oranının \% 88,47 yükseltilerek verim artışı sağlandığını belirtilmişlerdir. Sugözü vd. (2018) kütlece \% 4, \% 8 ve \% 12 oranlarında boraks ve üleksit içeren fren balata numuneleri üretmiş ve dökme demir disklerde bu numuneleri test etmiştir. Standartlara uygun olarak yapılan testler neticesinde boraks ve üleksitin bu tip uygulamalarda kullanılabilir olduğu ortaya koyulmuştur. Binici ve Durgun (2012), bazaltik pomza, barit, kolemanit ve yüksek fırın cürufu kullanılarak boya numuneleri hazırlanmış ve hazirlanan bu boyalarla kaplanan test donatılarının korozyon özelliklerini araştırmıştır. Çalışma sonunda, kolemanit ve barit ilaveli boyaların korozyona direnç gösterme bakımından diğer test numunelerinden daha iyi sonuçlar verdiği belirtilmiştir. Demirel ve Nasiroğlu (2017), kolemanit ve borik asit gibi bor mineralleri ve atıkların, inşaat endüstrisinde önemli parametreler olan çimento priz süresi, beton basınç dayanımı ve yalıtımsal özellik etkisi üzerine teorik bir çalışma yapmışlardır. Çalışma da özellikle bor mineralleri ve atıklarının inşaat ve çimento sektörü gibi sektör ve uygulamalarda kullanılabilirliği detaylı açıklamalarla vurgulamıştır. Morova ve Terzi (2015), atık kolemanit içeren agrega formda sıcak asfalt karışımları hazırlayarak bu atıkların ilgili sektörde kullanılan kireçtaşının yerine kullanılabilirliğini araştırmışlardır. $\mathrm{Bu}$ amaçla çeşitli oranlarda karışımlar hazırlayarak çeşitli karşılaştırmalar yapmışlardır. Çalışma sonunda, kolemanit atık nakliye maliyetlerinin kireçtaş1 maliyetlerinden daha düşük olması durumunda, kolemanit atıklarının sıcak asfalt üretiminde kullanılabilir olabileceğini belirtmişlerdir. Barış vd. (2018), Eti Maden Bigadiç Bor İşletme Müdürlüğünden temin edilen 8-125 mm Simav Ana Damar (SAD), Simav Tali Damar (STD) ve Tülü Sarı (TS) kolemanit cevherlerini, yakın kızılötesi (NIR) ve görünür ışı (CCD) kaynakları kullanarak zenginleştirilebilirliğini araştırmışlardır. Çalışmada, kullanılan cevherler kırma, eleme ve yıkama işlemlerinden geçirilerek kullanılan cihazlarda kullanıma en uygun tane boyutuna getirildiği belirtilmiştir. Çalışma sonunda, $\%$ 22,10-39,30 $\quad \mathrm{B}_{2} \mathrm{O}_{3}$ tenör aralığında beslenen cevherlerde 3,90-9,10 birim zenginleştirme sağlandığ 1 ve \% 93'ün üzerinde verimle yapılan zenginleştirme sonras1 \% 2,20-11,10 $\mathrm{B}_{2} \mathrm{O}_{3}$ tenör aralığında atıkların açığa çıktığı belirtilmiştir. Kütük ve Kara (2018), \% 0-5 oran aralığındaki kolemaniti çimento içerisine karıştırarak beton numuneler üretmiş ve bu beton numunelerin ultra ses geçiş hızı ve basınç 
dayanımları üzerine araştırma yapmışlardır. Çalışma sonunda, \% 3 kolemanit içeren test numuneleri ile alınan deney sonuçlarının en verimli sonuçlar olduğu belirtilmiştir. Güngören (2012), bor minerallerinin, konvansiyonel şartlardaki ve mikrodalga enerji uygulanmasından sonra gerçekleşen sudaki çözünmesine bağlı katı kayıplarını araştırmışlardır. Çalışma sonunda, normal şartlarda yapılan çözünürlük testlerinde sıcaklık artışına bağlı olarak hem kolemanit hem de üleksit numunelerinin çözünürlüğe bağlı katı kayıplarının arttığı, pülpte katı oranı artışına bağlı olarak ise azaldığı belirtilmiştir. Mikrodalga ön işlemli testlerde ise mikrodalga güç seviyesi arttıkça çözünürlüğe bağlı katı kaybının azaldığı ve uygulanan her bir güç seviyesinde mikrodalga enerjiye maruz kalma süresi arttıkça çözünürlüğe bağlı katı kayıplarının yine bir miktar azaldığını belirtilmiştir. Arslan ve Bayat (2012), Eti Maden Emet Bor İşletmesinden temin edilen kolemanit numunelerine karıştırmalı ve kolon biyoliçi yöntemleri uygulayarak $\mathrm{B}_{2} \mathrm{O}_{3}$ çözünme verimlerini araştırmışlardır. Çalışma sonunda, karıştırmalı biyoliçi çözünme veriminin kolon biyoliçi çözünme veriminden \% 20 oranında daha yüksek olduğu belirtilmiştir. Kuş vd. (2016), sıcak presleme yöntemi ile üretilen bronz matrisli fren balatalarının tribolojik özelliklerine kolemanit miktarının etkisini araştırmışlardır. Çalışma sonunda; tüm balata numunelerinin aşınma direnci ve sürtünme katsayı değerlerinin SAE-J661 standardına uygun olduğu, aşınma direnci bakımından en iyi sonucu kolemanit içermeyen balatanın verdiği ve sürtünme katsayısı açısından en iyi sonucu da \% 0,5 kolemanit içeren balatanın verdiği belirtilmiştir.

Görüldüğü üzere literatürdeki çalışmaların büyük bir kısmı; çimento, beton, asfalt, fren balatası, metalürjik pelet, atık, cüruf ve boya gibi malzemelere kolemanit ilavesinin etkileri üzerinedir. Sınırlı sayıdaki çalışmalarda ise kolemanit cevher ve atıkların zenginleştirilmesi amaçlanmaktadır. $\mathrm{Bu}$ çalışmada ise, toz altı kaynak tozu üretiminde belirli oranlarda kolemanit kullanılarak, cüruf ve kaynak metalinin tipik özelliklerine kolemanitin etkisi araştırılmıştır.

\section{Materyal ve Metot}

\subsection{Hammadde temini}

Çalışmada, öncelikle Eti Maden İşletmeleri Bigadiç Bor İşletme Müdürlüğü, Balıkesir işletmesinden kolemanit temini sağlanmıştır. Toz üretiminde kullanmak üzere flaks olarak $\mathrm{CaF}_{2}, \mathrm{CaO}, \quad \mathrm{TiO}_{2}, \quad \mathrm{MnO}, \quad \mathrm{K}_{2} \mathrm{O}, \quad \mathrm{Na}_{2} \mathrm{O}$ hammaddeleri Tekomi Metal Sanayi ve Dış Ticaret Limited. Şirketi, İstanbul firmasından temin edilmiştir. Toz üretim maliyetlerini düşürmek amaciyla Etikrom Anonim şirketi, Elazı ̆ firmasından ferrokrom atığ (\% 33,7 $\mathrm{MgO}, \% 31,2 \mathrm{SiO}_{2}$ ve \% 29,9 $\mathrm{Al}_{2} \mathrm{O}_{3}, \%$ 2,6 $\mathrm{Cr}_{2} \mathrm{O}_{3}, \%$ 1,45 $\mathrm{CaO}, \% \quad 0,9 \mathrm{FeO}$ ) temini sağlanmıştır. Toz üretiminde kullanmak amaciyla, mukavemet ve deoksidan karakterdeki ferro mangan (FeMn) ve ferro molibden (FeMo) yine Tekomi Metal Sanayi ve Dış Ticaret Limited. Şirketi, İstanbul firmasından temin edilmiştir. Benzer şekilde, tozların bağ yapısının güçlenmesi amacıyla kullanilan sodyum silikat $\left(\mathrm{Na}_{2}\left(\mathrm{SiO}_{2}\right)_{\mathrm{n}} \mathrm{O}\right)$ bağlayıcısı da yine Tekomi Metal Sanayi ve Dış Ticaret Limited. Şirketi, İstanbul firmasından temin edilmiştir. Substrat olarak kullanılan SAE 1020 çelik levhalar Harput Gülengül Sanayi ve Ticaret Limited Şirketi, Elazı ̆̆ firmasından temin edilmiştir. Son olarak kaynak tozları ile birlikte kombine edilerek kullanılan AWS-EL-12 (S1) kaynak elektrotları, Oerlikon Kaynak Elektrotları ve Sanayi Anonim Şirketi, Manisa firmasından temin edilmiştir.

\subsection{Bigadiç kolemanit içeren toz altı kaynak tozu üretimi}

Çalışmada, aglomere metot kullanılarak kaynak tozu üretimleri gerçekleştirilmiştir. $\mathrm{Bu}$ metodun pratik ve ferro alaşım ve ilave flaks bileşeni eklemeye uygun olması sıklıkla tercih 
Tablo 2. SAE 1020 çeliği ve AWS-EL-12 elektrotunun kimyasal kompozisyonları.

\begin{tabular}{|c|c|c|c|c|c|c|}
\hline \multirow[t]{2}{*}{ Malzeme } & \multicolumn{6}{|c|}{ Kimyasal Kompozisyon ( \% Ağılıkça) } \\
\hline & $\mathrm{C}$ & $\mathrm{Si}$ & $\mathrm{Mn}$ & $\mathrm{P}$ & $\mathrm{S}$ & $\mathrm{Fe}$ \\
\hline SAE 1020 çeliği & 0,158 & 0,281 & 0,648 & 0,033 & 0,034 & Kalan \\
\hline \multirow[t]{2}{*}{ Malzeme } & \multicolumn{6}{|c|}{ Kimyasal Kompozisyon ( \% Ağılıkça) } \\
\hline & $\mathrm{C}$ & $\mathrm{Si}$ & $\mathrm{Mn}$ & & $\mathrm{Fe}$ & \\
\hline AWS-EL-12 elektrot & 0,07 & 0,05 & 0,50 & & Kalan & \\
\hline
\end{tabular}

Gerçekleştirilen tüm kaynak testleri $500 \mathrm{~A}$ akımda, $28 \mathrm{~V}$ gerilimde, $50 \mathrm{~cm} / \mathrm{dk}$ kaynak hızlarında ve 3,2 mm lik kaynak tel çapına sahip tellerle gerçekleştirilmiştir. Tüm testlerde elektrot pozitif olarak ayarlanmıştır. Kaynak testlerinde dikiş özelliklerine doğrudan etki eden meme boyu ya da stickout mesafesi standartlara uygun şekilde kullanılan tel çapının (3,2 mm) 10 katı olarak belirlenerek tüm numunelerde standart olarak $3.2 \mathrm{~cm}$ mesafede tercih edilmiştir. Kaynak testlerinde ortaya çıkan 1sı girdisi $\mathrm{H}=60$. E. I / $1000 \mathrm{~S}$ formülü ile hesaplanmıştır. Burada $\mathrm{H}$ 1S1 girdisi, E voltaj, I akım ve S kaynak hızını temsil etmektedir (Akbari and Far 2009; Nowacki and Rybicki, 2005). Benzer şekilde 1s1l verim ile birlikte net 1s1 girdisi de hesaplanmıştır. $\mathrm{Bu}$ amaçla, $\mathrm{HI}=\eta$. $\mathrm{H}$ formülünden yararlanılmıştır. $\mathrm{Bu}$ formülde; HI Net 1s1 girdisi, $\eta$ verim katsay1s1 ve $H$ is1 girdisini temsil etmektedir (Kou 2003; Melfi 2010). Toz altı kaynak tekniğinin verim katsayısı maksimum değer olan 1 olarak alınmıştır (Bause and Mihalisin, 1989; Kou, 2003; Melfi, 2010). Bu veriler kullanılarak net 1S1 girdisi hesaplanmıştır. Kaynak parametreleri Tablo 3'de verilmektedir.

Tablo 3. Kaynak testlerinde kullanılan kaynak parametreleri.

\begin{tabular}{|c|c|c|c|c|c|c|}
\hline Numune & Voltaj (V) & Amper (A) & $\begin{array}{c}\text { Kaynak Hızı } \\
(\mathrm{cm} / \mathrm{dk})\end{array}$ & Elektrot & Stick-out (mm) & $\begin{array}{l}\text { Net Is1 girdisi } \\
(\mathrm{kj} / \mathrm{mm})\end{array}$ \\
\hline 1 & 28 & 500 & 50 & + & 32 & 1,68 \\
\hline 2 & 28 & 500 & 50 & + & 32 & 1,68 \\
\hline 3 & 28 & 500 & 50 & + & 32 & 1,68 \\
\hline 4 & 28 & 500 & 50 & + & 32 & 1,68 \\
\hline 5 & 28 & 500 & 50 & + & 32 & 1,68 \\
\hline
\end{tabular}

\subsection{Mikro yapt, kimyasal kompozisyon, sertlik ve aşınma testleri}

Çalışmada gerçekleştirilen kaynak testleri neticesinde elde edilen kaynak dikişleri, öncelikle cürufun kolay kalkması, kaynak dikişinin geometrisi, yüzey pürüzlülüğü ve gözenek var olup olmama gibi parametreler göz önünde bulundurularak incelenmiştir. Görsel olarak incelenen kaynak dikişleri 12x10x10 mm ebatlarında olacak şekilde, labaratuvar tipi sulu kesme makinesinde kesilmiştir. Kesilen numuneler klasik metalografik yöntemlerle zımparalama ve parlatma işlemlerine tabi tutulmuş ve $\% 2$ nital çözeltisinde dağlanmıştır. Dağlanan numunelerin mikroskobik olarak incelenmesin de Nikon Eclipse-MA200i optik mikroskobu ve kimyasal kompozisyon 
analizlerinde ise optik emisyon spektrometresi kullanılmıştır. Taramalı elektron mikroskobu incelemelerinde (SEM) Jeol Inca $\mathrm{x}$-act JSM-7001f makinesinden yararlanılmıştır. Ayrıca; mikro yapılardaki faz ve bileşiklerin tayini için ise Rigaku RadBDmax2 makinesi yardımıyla $X$-ışını analizleri yapilmıştır.

Kaynak bölgesinin enine kesitinden hazırlanan $12 \times 10 \times 10 \mathrm{~mm}$ boyutlarındaki numunelerin sertlik ölçümleri makro olarak gerçekleştirilmiştir. Makro sertlik ölçümleri Vickers sertlik ölçüm metodu kullanılarak gerçekleştirilmiştir (Kahraman vd., 2010). Sertlik ölçümü amaciyla kesilen numuneler yüzeylerindeki kir, pas vb. pisliklerden arındırıldıktan sonra zımparalama ve parlatma işlemleri ile sertlik ölçümüne uygun hale getirilmiştir.

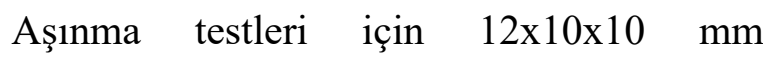
ebatlarında numuneler çıkartılmış ve bu numuneler $920 \mathrm{~mm}$ boy ve $100 \mathrm{~mm}$ genişliğe sahip bant zımparalarda aşınma testine tabi tutulmuştur. Aşınma testleri 80 mesh su zımparas1, 20 newton yük, 50 metre kayma mesafesi ve 300 devir/dakika da gerçekleştirilmiştir. Deneysel testler öncesi ve sonrası ağırlıklar ölçülerek aşınma kayıpları bulunmuştur. Daha objektif sonuçlar için her bir testte yeni bir zımpara kullanılmış ve aşınma kayıpları yüzdelik değerler şeklinde hesaplanmıştır.

\section{Bulgular ve Tartışma}

\subsection{Kimyasal analizler ve mikro yapt analizleri}

Artan kolemanit miktarına bağlı olarak hazırlanan tozlar ve bu tozlardan elde edilen dolgu ve birleştirme amaçlı kaynaklı parçaların dikiş ve cüruf görüntüleri Şekil 1 'de verilmektedir.

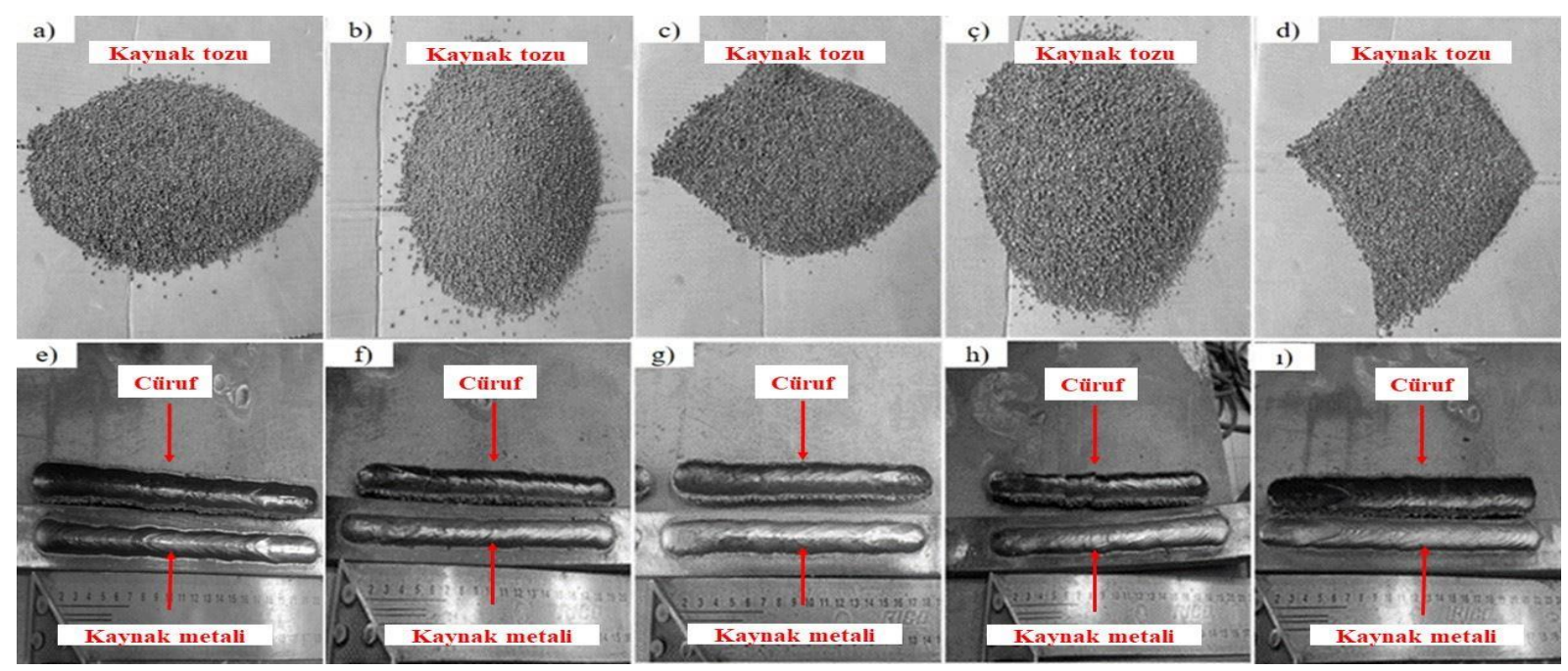

Şekil 1. Artan kolemanit miktarına bağlı olarak hazırlanan tozlar ve bu tozlardan elde edilen dolgu ve birleştirme amaçlı kaynaklı parçaların dikiş ve cüruf görüntüleri. a,e) \% 0 kolemanit, b,f) \% 1 kolemanit, c,g) \% 2 kolemanit, ç,h) \% 3 kolemanit, d,1) \% 4 kolemanit.

Şekil 1'de verilen aglomere tozlar incelendiğinde; hazırlanan tüm tozların tane boyutlarının birbirine benzer büyüklükte olduğu ve herhangi bir topaklanma gibi bir durumun olmadiğı görülmektedir. Fakat, özellikle daha fazla oranlarda kolemanit içeren tozların mukavemetinin diğerlerine oranla daha yüksek olduğu deneysel işlemler esnasında gözlemlenmiştir. Bu durum Eti Maden, (2018) raporlarında belirtilen döküm esnasında cürufun tek parça halinde alınmak amacıyla kullanımına ve camsı özellik katma 
özellikleri ile örtüşmektedir. Tüm numunelerde aynı oranda bağlayıcı kullanılmasına rağmen toz mukavemeti en iyi olan numuneler kolemanit içeren tozlardır. Kolemanit içeren tozlar arasında, en yüksek mukavemete sahip olan toz \% 4 kolemanit içeren toz iken, en düşük olan ise $\% 1$ kolemanit içeren toz ile elde edilmiştir. Diğer numunelerin toz mukavemetleri arasinda bariz bir fark bulunmamaktadır.

Hazırlanan tozlar ile elde edilen kaynak dikişlerinin genişliğinde ise herhangi bir değişiklik olmamıştır. Burada; dikiş genişliğinin artmamasının nedeni, toz içerisinden kaynak metaline eşit oranda ve eser miktardaki alaşım elementinin geçmiş olmasıdır. Benzer şekilde tüm numunelerde homojen formda kaynak dikişleri tespit edilmiştir.

Tüm kaynak dikişleri çatlak, poroz ve benzer kusurlar açısından yüzeye açık bir şekilde incelendiğinde; kaynak özelliklerini negatif etkileyebilecek ciddi bir hata bulunmadığ1 tespit edilmiştir. Hazırlanan numunelerle yapılan kaynak testleri cürufun kendiliğinden kalkması açısından değerlendirildiğinde; tüm kaynak testlerinde cürufun yüzeyden kendiliğinden kalkmasında herhangi bir problem olmamıştır. Tüm kaynak testlerinde kaynak dikişinin parlak ve pürüzsüz olduğu tespit edilmiştir. $\% 0, \% 1$ ve $\% 2$ kolemanit içeren numunelerde kalkma kolay ve kendiliğinden gerçekleşmiştir. Diğer iki numunede özellikle \% 3 ve \% 4 kolemanit içeren tozlar ile yapılan test sonuçlarında ise, cürufun yüzeyden kendiliğinden daha geç sürelerde kalktığ 1 gözlemlenmiştir. Toz bileşiminde kullanılan kolemanitin ergime noktasinın $986{ }^{\circ} \mathrm{C}$ olmasi nedeniyle, toz karışımının toplam ergime noktası da düşmektedir. Ergime noktası düşen toz karışımının (flaks) akışkanlığı artmakta, oluşan cüruf daha geç soğumakta ve oluşan cürufun yüzeyden daha uzun sürelerde kalkmasına neden olmaktadır (Eti Maden, 2018).

Kaynak metalinden alınan ve optik emisyon spektrometresi kullanılarak gerçekleştirilen kimyasal kompozisyon analiz sonuçları Tablo 4'de verilmektedir.

Tablo 4. Kimyasal kompozisyon analiz sonuçları.

\begin{tabular}{ccccccc}
\hline Numune numarası & İçerik & $\mathbf{C}$ & $\mathbf{M n}$ & Mo & Si & Fe \\
\hline $\mathbf{1}$ & \% 0 kolemanit & 0,06 & 0,88 & 0,19 & 0,20 & Kalan \\
\hline $\mathbf{2}$ & \% 1 kolemanit & 0,06 & 0,89 & 0,19 & 0,20 & Kalan \\
\hline $\mathbf{3}$ & \% 2 kolemanit & 0,06 & 0,86 & 0,18 & 0,21 & Kalan \\
\hline $\mathbf{4}$ & \% 3 kolemanit & 0,06 & 0,95 & 0,19 & 0,19 & Kalan \\
\hline $\mathbf{5}$ & \% 4 kolemanit & 0,06 & 0,93 & 0,17 & 0,21 & Kalan \\
\hline
\end{tabular}

Dolgu ve birleştirme amaçlı kullanmak amaciyla üretilen ve içerisinde artan miktarda kolemanit bulunan/bulunmayan tozlar ile elde edilen kaynaklı numunelerden alınan kimyasal kompozisyon analizlerinde, toz içerisinden kaynak metaline geçen alaşım elementi miktarı eser miktarda olduğu için AWS-EL-12 (S1) elektotunun tipik kompozisyonuna benzer sonuçlar elde edilmiştir (Askaynak, Gedikkaynak, Oerlikon
19 Kasim 2018). Bu kompozisyonlarda ortalama olarak \% 0.06 karbon, \% 1 mangan, \% 0.20 molibden ve silisyumun kaynak metalinde yer aldığ 1 tespit edilmiştir.

Artan miktarlarda kolemanit içeren/içermeyen kaynak tozları ile elde edilen kaynaklı test numunelerinin optik mikroskop kullanılarak gerçekleştirilen mikro yapı fotoğrafları Şekil 2'de verilmektedir 


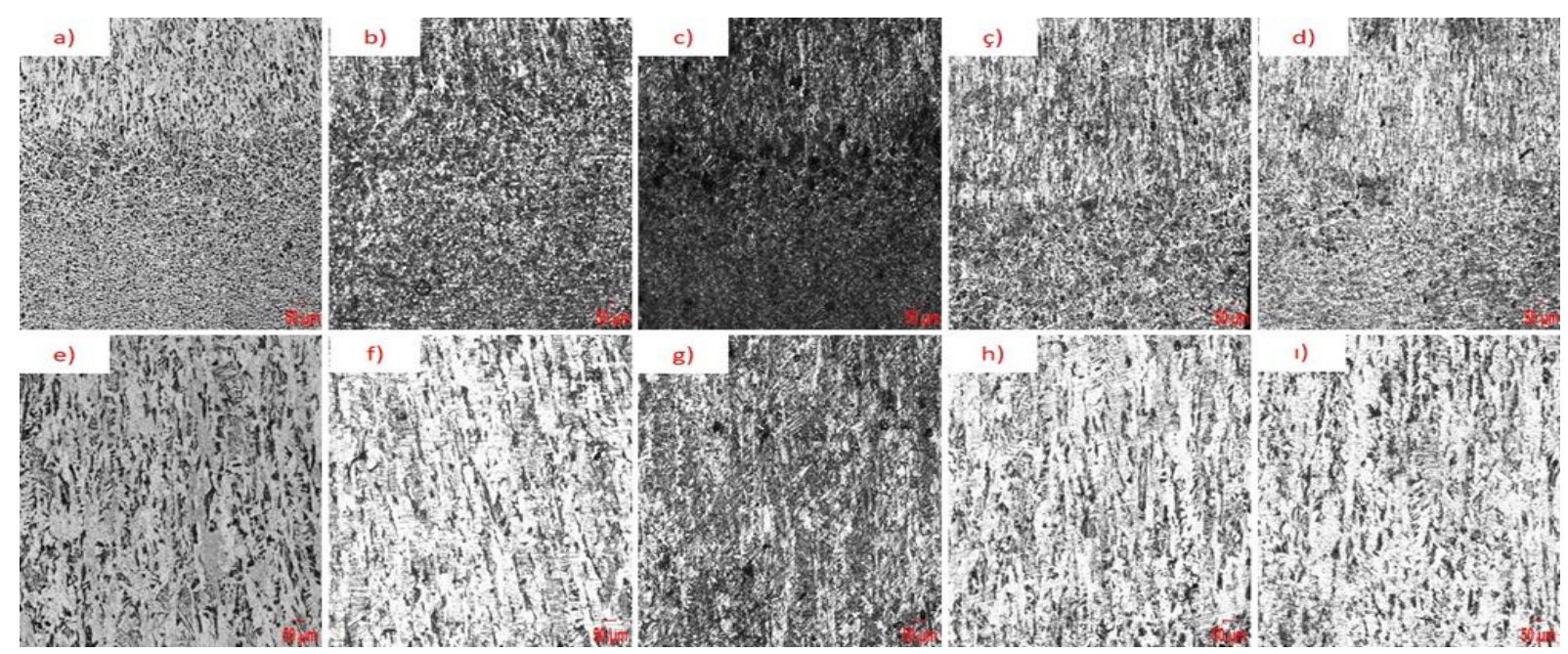

Şekil 2. Kolemanit miktarına bağlı olarak elde edilen kaynaklı parçaların geçiş ve dikiş bölgesinden alınan mikro yapı fotoğrafları a, e) \% 0 kolemanit, b, f) \% 1 kolemanit, c,g) \% 2 kolemanit, ç, h) \% 3 kolemanit, d, 1) \% 4 kolemanit.

Mikro yapılarda kararlı olan fazlar ferrit ve perlit yapılarıdır. Mikro yapı kompozisyonlarında karbon yüzdesinin \% 0.06 olduğu hatırlandığında mikro yapının büyük bir kısmının ferritten oluşması ve az miktarda perlitin mikro yapıda yer alması

gerekmektedir. Mikro yap1 incelemelerinde, kompozisyon analizleri ile uyumlu ferrit ve perlit mikro yapılar tespit edilmiştir. Mevcut fazlar, XRD (Şekil 3) ve literatür (Savaşkan, 2009) ile desteklenmiştir.

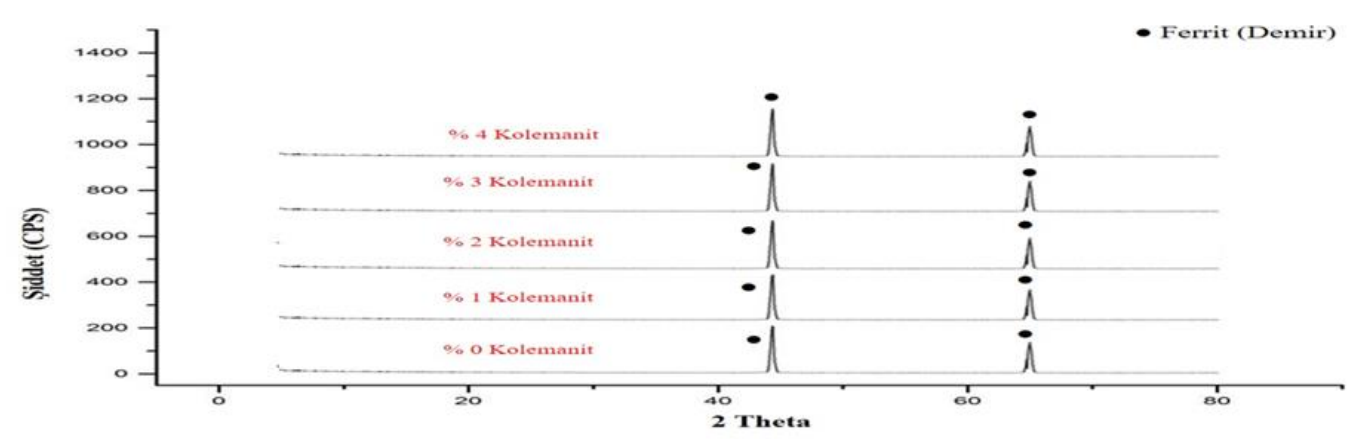

Şekil 3. XRD analiz sonuçları.

Kolemanit içeren tozlarla yapılan kaynak testleri neticesinde elde edilen kaynak metalinin, soğuması esnasında ilk olarak $\delta$ demir katı çözeltisi (fazı) oluşmuştur. Geriye kalan ergiyik (sıv1 metal) ve $\delta$ demiri peritektik reaksiyonla östenit $(\mathrm{\gamma})$ demir katı çözeltisine dönüşmüştür. Östenit fazı $\mathrm{AC}_{3}$ katılaşma çizgisine kadar kararlı kaldıktan sonra $\left(\mathrm{AC}_{3}-\mathrm{AC}_{1}\right)$ çizgisi aralığındaki sıcaklıklarda ferrit+östenit katı çözeltisini oluşturmuştur. Bu katı çözelti ötektoid nokta olan $\left(\mathrm{AC}_{1}\right.$ çizgisi ya da $\left.723{ }^{\circ} \mathrm{C}\right)$ ye kadar kararlı kalmış bu sıcaklığın altındaki sıcaklıklarda ferrit aynı şekilde kalmış geriye kalan östenit ise lokal olarak içerdiği karbon miktarına bağlı olarak allotropik dönüşüme uğrayarak ferrit ve perlit dönüşümünü tamamlamıştır (Savaşkan, 2009). Böylece, ferrit ve perlite fazları oluşmuştur (Şekil 4). 

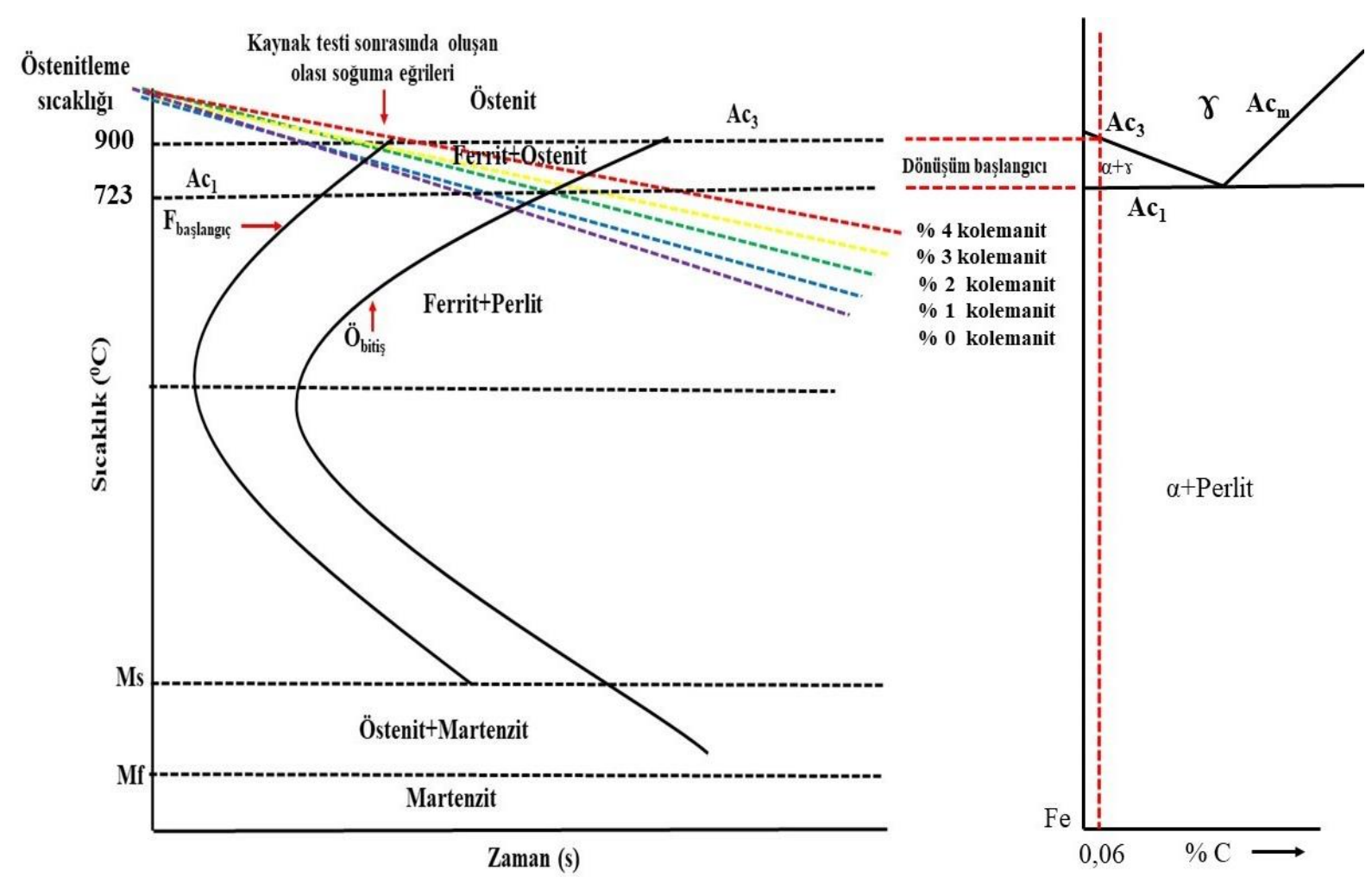

Şekil 4. Kaynaklı parçaların soğuması esnasında oluşan fazları gösteren Fe-C denge diyagramı, TTT diyagramı ve soğuma eğrileri (Savaşkan, 2009).

Kolemanit içeren tozlar ile kaynak testleri neticesinde elde edilen kaynak metallerinin mikro yapıları kolemanit yüzdesine bağlı olarak karşılaştırıldığında; \% $0, \% 1$ ve \% 2 kolemanit içeren numunelerde benzer irilikte taneler tespit edilmişken, $\% 3$ ve $\% 4$ kolemanit içeren tozlarda ise tane yapısının daha kaba olduğu tespit edilmiştir. Ayrıca; tüm mikro yapılarda yöntemin bir özelliği olan yönlenmiş tane yapısı da gözlemlenmiştir.

Toz bünyesinde bulunan kolemanitin kaynak metalinde bulunan faz ve bileşiklere etki etmediği yapılan mikro yapı analizleri ve kimyasal kompozisyon analizleri ile tespit edilmiştir. Ancak; daha önce belirtildiği üzere toz bünyesindeki artan miktardaki kolemanit mikro yapıdaki tanelerin kabalaşmasına ve irileşmesine neden olmuştur. Kolemanitin, cüruf oluşturucu özelliğinin olması, artan kolemanite bağlı olarak kaynak esnasında oluşan cürufu daha geç (uzun sürelerde) kaynak metalinden kaldırması ve cürufu tek parça halinde tutarak mukavemetini arttırması hatırlandığında; bu durumun olası olduğu anlaşılmaktadır. İyi bilindiği üzere çelikler allotropik dönüşüme uğrayabilmekte ve soğuma hızına bağlı olarak kaba ve ince tane yapısı oluşturabilmektedir. Tane yapısının da mukavemeti doğrudan etkilediği düşünüldüğünde, kolemanitin bu etkisinin negatif olduğu düşünüle bilinir. Fakat daha yüksek oranlarda alaşım elementi ve karbon içeren ve soğuma hızının düşük olması istenen durumlarda özellikle hızlı soğuma nedeniyle oluşabilecek çatlak oluşumunu engellemede bu durumun pozitife dönüştürülerek kullanıla bilineceği düşünülmektedir. Düşük karbonlu çeliklerde kabalaşma etkisi gösteren kolemanit daha yüksek alaşım ve karbon içeriğine sahip çeliklerde, daha yavaş soğutma yani cürufun kaynak metalinden daha uzun sürelerde kalkma özelliği sayesinde, soğumayı yavaşlatarak kaynak esnasında oluşabilecek çatlak oluşumunu engelleyebileceği öngörülmektedir. 


\subsection{Sertlik ve aşınma testleri}

Kaynak tozu içerinde kolemanit kullanılarak/ kullanılmadan (\% $0-4)$ elde edilen kaynaklı parçalardan alınan numunelerin enine ve boyuna 5 er farklı bölgesinden alınan ve ortalama değerler olarak hesaplanan makro sertlik ölçüm sonuçları Şekil 5'de verilmektedir.

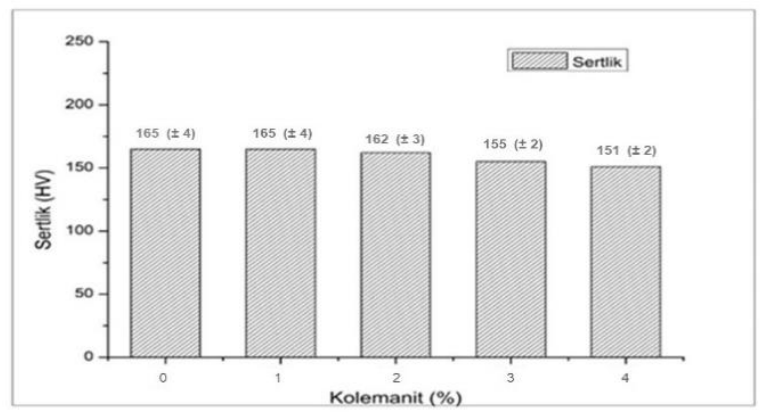

Şekil 5. Kaynaklı parçalardan alınan makro sertlik test sonuçları.

Sertlik sonuçları incelendiğinde; $151 \mathrm{HV}$ ile en düşük sertliğe sahip kaplama $\% 4$ kolemanit içeren numune iken $165 \mathrm{HV}$ ile en yüksek sertliğe sahip kaplama \% 0 ve $\% 1$ kolemanit içeren numunelerdir. Açıkça görüldüğü üzere; kolemanit miktarının artması kısmi olarak da olsa sertlik düşüşüne sebep olmuştur. Bu durum, artan kolemanit miktarının soğuma esnasında kaynak metalinden daha uzun sürelerde kalkmasıyla ilişkilendirilmektedir. Cürufun daha geç sürelerde kaynak metalinden ayrılması, çeliklerin soğuma hızına bağlı olarak ince ya da kaba tane yapısina sahip olabilmesi, ince tane yapısının mukavemeti arttırması ve kaba tane yapısının mukavemeti düşürmesi nedeniyle, mikro yapı analizlerinde belirtilen kaba tanelerin bu sertlik düşüşünün ana nedeni olabileceği düşünülmektedir. Mevcut sertlik sonuçları AWS-EL-12 (S1) elektrotu kullanılarak elde edilen sertlik sonuçları ile benzerlik göstermektedir (Askaynak, Gedikkaynak, Oerlikon, 19 Kasım 2018). Ancak, dolgu ve birleştirme amaçl1 kullanılmak üzere kaynak tozu bünyesinde kolemanit etkisini araştıran ya da toz bünyesine kolemanit katarak bilimsel ya da ticari bir araştırma yapılan bir çalışma bulunamamıştır.

Toz içerisindeki kolemanit miktarına bağlı olarak elde edilen kaynaklı parçalardan 80 mesh su zımparası, $20 \mathrm{~N}$ yük, $50 \mathrm{~m}$ kayma mesafesi ve 3000devir/dk aşınma hızında yüzdesel olarak hesaplanmış aşınma kayıpları Şekil 6'da ve aşınmış yüzeylerden alınan SEM fotoğrafları Şekil 7'de verilmektedir.

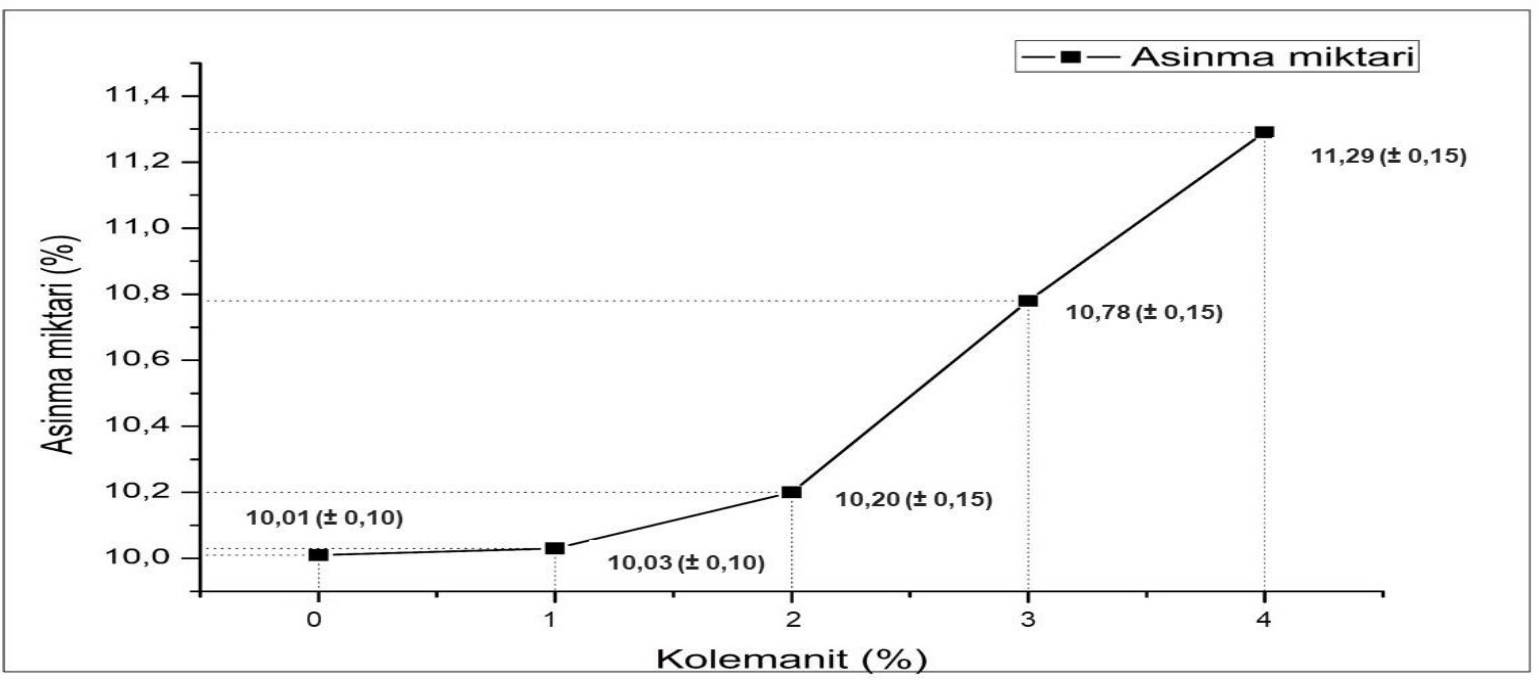

Şekil 6. Artan kolemanit miktarına bağlı olarak elde edilen kaynaklı parçaların yüzdesel olarak hesaplanmış aşınma kayıpları. 

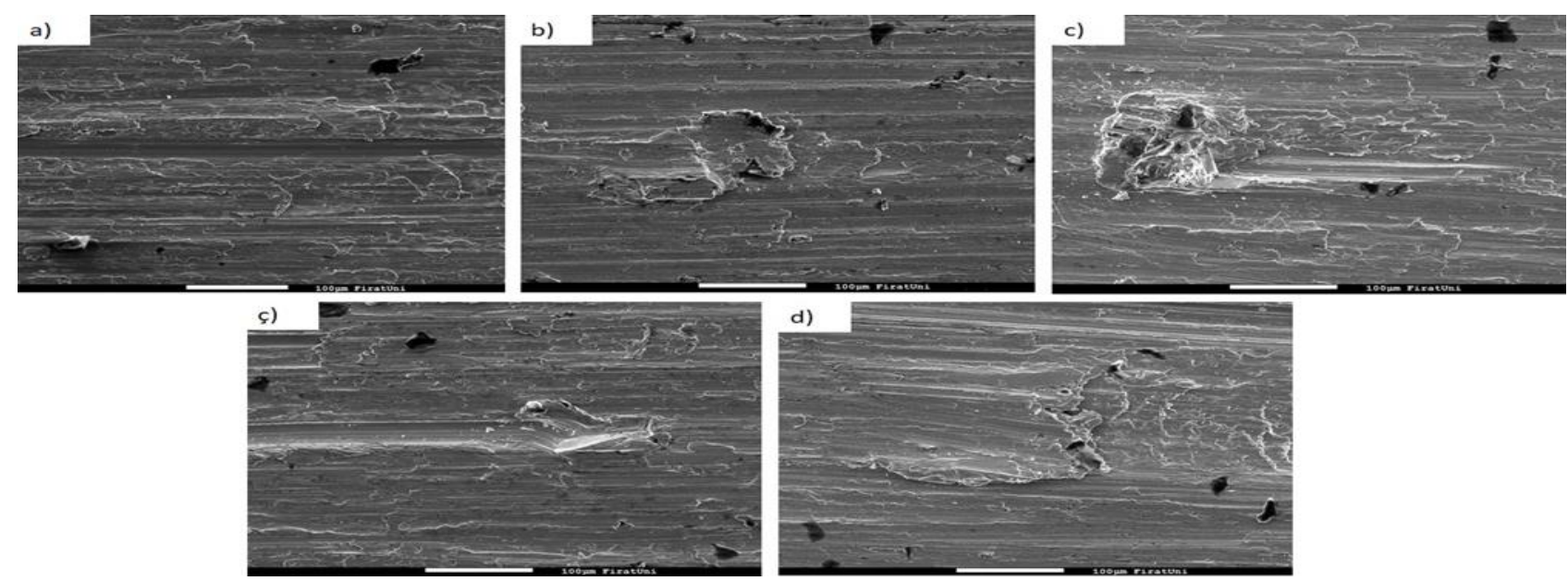

Şekil 7. Artan kolemanit miktarına bağlı olarak elde edilen kaplamaların aşınmış yüzey SEM fotoğrafları. a) $\% 0$ kolemanit, b) $\% 1$ kolemanit, c) $\% 2$ kolemanit, ç) $\% 3$ kolemanit, d) $\% 4$ kolemanit.

Yüzdesel olarak hesaplanmış aşınma kayıpları incelendiğinde; en fazla aşınma miktarı \% 11.29 ile \% 4 kolemanit içeren toz ile elde edilen numunede iken en az aşınma miktarı ise $\% 10.01$ ile $\% 0$ kolemanit içeren toz ile elde edilen numunede elde edilmiştir. Hazırlanan toz bünyesindeki kolemanit miktarındaki artış aşınma kayıplarının artmasına neden olmuştur. Bu durum daha yüksek miktardaki kolemanit içeren tozların kaynak metalinden daha uzun sürelerde kalkmasiyla ve bu nedenle de daha yavaş soğuma nedeniyle oluşan kaba tane yapısı ile ilişkilendirilmiş̧ir. Bu durum Hall-Petch eşitliğiyle de paralellik göstermektedir. $\sigma($ akma dayanımı $)=\sigma 0$ (sabit) $+\mathrm{k}$ (sabit) d (ortalama tane boyutu)-1/2 Hall-Petch eşitliğine göre, tane boyutunun incelmesi malzemenin mukavemetini arttırmakta, tane irileşmesi( kabalaşması) ise mukavemeti düşürmektedir. Çeliklerin allotropik karakterde olmaları nedeniyle soğuma hızına bağlı olarak tane yapısı ve mukavemet özellikleri değişebilmektedir. Toz altı kaynağında cürufun yüzeyden daha uzun sürelerde kalkması, elde edilen kaynak metalinin çelik karakterde olması nedeniyle tane yapısını etkilemektedir. Soğumanın yavaşlamasıyla oluşan taneler daha kaba ve iri boyutlarda olmuş ve bu durum da kaynak metalinin sertliğinin düşmesine neden olmuştur. Sertliğin düşmesi ise doğrudan aşınma direncinin düşmesine ve aşınma kayıplarının artmasına neden olmuştur (Lehto et al., 2014; Zhao et al., 2006; Liu et al., 2003).

Aşınmış yüzeylerin SEM fotoğrafları yüzey karakteristiği açısından incelendiğinde; artan kolemanit miktarına bağlı olarak elde edilen test numunelerinin aşınma çizgilerinin kalınlaştığı ve daha geniş alanlara yayılan aşınma çizgilerinin ve bölgesel kazıma bölgelerinin varlığ 1 tespit edilmiştir. Benzer sertliklere sahip kaynak metallerinin varlığına rağmen, kolemanit içermeyen test numunesinde süreklilik arz eden aşınma çizgisi bulunurken, diğer kolemanit içeren test numunelerinde süreklilik arz etmeyen ve daha geniş bölgesel kazıma bölgeleri tespit edilmiştir. Bu durum, kolemanit içeren test numunelerinin, daha yumuşak tane yapısına sahip olmaları ile ilişkilendirilmiştir. Yumuşak tane yapısına sahip test numuneleri plastik olarak yüzeye sıvanarak daha geniş ve süreksiz kazıma bölgeleri oluşturmuşlardır. Kolemanit içeren aşınmış yüzeylerde bölgesel olarak kazıma bölgelerinin yoğun olarak bulunduğu ve bu nedenle de aşınma kayıplarının daha fazla oranlarda olduğu belirlenmiştir. Kolemanit içermeyen numune ile elde edilen kaynak metalinin aşınma çizgisi dışındaki 4 numunede de birbirine benzer aşınmış yüzeyler olup bu durum 
birbirine yakın sertlik değerleriyle ilişkilendirilmiştir.

\section{Sonuç}

$\mathrm{Bu}$ sonuçlara göre; dolgu ve birleştirme amaçlı hazırlanan kaynak tozlarında artan miktardaki Bigadiç kolemanit, toz mukavemetinin artmasına, kaynak metalinde pürüzsüz ve parlak bir yüzey oluşmasına, kaynak esnasında oluşan cürufun ergime noktasının düşmesine, cüruf akışkanlığının artmasına, cürufun daha geç soğumasına cürufun yüzeyden daha uzun sürelerde kalkmasına ve buna bağlı olarak da kaynak metalinin daha yavaş soğumasına neden olmaktadır. $\mathrm{Bu}$ nedenle kullanılan kolemanitin cüruf oluşturucu olarak kullanılabileceği, daha parlak kaynak dikişinin önem kazandığı uygulamalarda kullanılabileceği ve kaynak metalinde kompozisyona ve soğuma hızına bağlı olarak oluşabilecek çatlak oluşumunu engellemede kullanılabileceği önerilmektedir. Artan miktarda kolemanit içeren kaynaklı parçalarda, kaplamalarda benzer ferrit ve perlit yaplarının bulunduğu, sertliklerin artan kolemanit yüzdesiyle $165 \mathrm{HV}$ den $151 \mathrm{HV}$ sertliğe düştüğü ve artan kolemanit miktarı ile aşınma kayıplarının arttı̆̆ belirlenmiştir.

\section{Teşekkür}

$\mathrm{Bu}$ çalışma, Tübitak (Türkiye Bilimsel ve Teknolojik Araştırma Kurumu) 114M016 numaralı proje kapsamında desteklenmiştir. Desteklerinden dolayı, TÜBİTAK başkanlığına ve tüm çalışanlarına teşekkür ederim.

\section{Kaynaklar}

Akbari, D., Far S. 2009. " Effect of The Welding Heat Input on Residual Stresses in Butt-Welds of Dissimilar Pipe Joints," International Journal of Pressure Vessels and Piping, Volume 86, Issue 11, 769-776.

Arslan, V., Bayat, O. 2012. 'Karıştırmalı ve Kolon Biyoliçi Yöntemleri ile Kolemanit
Cevherinden Borik Asit Üretimi', Bilimsel Madencilik Dergisi, 51 (1), 3-12.

Barış, M., Metin, F., Karabulut, N., Özyücel, F. 2018. "8-125 mm Kolemanit Cevherinin NIR/CCD Optik Ayırıc1 ile Zenginleştirilmesi', Gazi Üniversitesi Fen Bilimleri Dergisi Part C: Tasartm Ve Teknoloji, 6 (2), 414-425.

Başar, G., Buldum B.B., Sugözü İ. 2018. 'Kolemanit ve Boraks Takviyeli Fren Balatalarının Sürtünme Performansı', ElCezerî Fen ve Mühendislik Dergisi, (ElCezerî Journal of Science and Engineering) Cilt: 5, No: 2, 635-644.

Bause, G.K., Mihalisin, J.R. 1989. ' Metallurgy of Investment Cast Superalloy Components", Superalloys, Supercomposites and Superceramics, 99-148.

Bideci, Ö., S.,Bideci, A. 2018. '’Öğütülmüş Kolemanit Katkısının Çimento Harçlarına Etkisi',, Firat Üniv. Müh. Bil. Dergisi (Science and Eng. J. of Firat Univ.) Cilt 30(1), 133-138.

Binici, H., Durgun, M. 2012. 'Katk1l1 Boyalarla Kaplanan Betonarme Donatılarının Korozyon Performans1', Teknik Dergi, 23 (114), 6141-6162.

Çiftçi, H., Atik, S. 2015.' Kolemanit Artığının Mekanik Așındırma ve Isı ile Dağıtma Yöntemleri ile Zenginleştirilmesi", Suleyman Demirel University of Journal of Natural and Applied Science, Cilt 19(1), 5762.

Davis, J.R. 1993. "ASM Handbook: Welding, Brazing and Soldering, Vol.6, ASM International, USA.

Demir, İ., Güngören, C., Özkan, Ș. 2017. "Effect of Microwave Energy on the Comminution and Flotation of Colemanite Ore', Journal of Boron, 2 (2), 75-81.

Demirel, B., Nasıroğlu, S. 2017. 'Bor Mineralleri ve Atıklarının Cimentoda Kullanılma Stratejileri' Firat Üniversitesi Mühendislik Bilimleri Dergisi, 29 (1), 95-100. 
Eskibalci M.F., Ozkan S.G. 2012. “'An Investigation of Effect of Microwave Energy on Electrostatic Separation of Colemanite and Ulexite"' Minerals Engineering, vol.31, 9097.

Gül A., Kaytaz, Y., Önal G. 2006. ''Beneficiation of Colemanite Tailings by Attrition and Flotation", Minerals Engineering, vol.9, issue 4, 368-369.

Güngören, Ş. 2012. 'Mikrodalga Enerjisinin Kolemanit ve Üleksitin Sudaki Çözünürlügüne Etkisinin Araştırılması", İstanbul Yerbilimleri Dergisi, 22 (1), 85-93.

http://www.askaynak.com (19 Kasım 2018)

http://www.etimaden.gov.tr/kolemanit(19Kas $1 \mathrm{~m} 2018)$

http://www.gedikkaynak.com.tr $(19$ Kasım 2018)

http://www.oerlikon.com.tr (19 Kasım 2018)

Kahraman, N., Gülenç, B., Durgutlu, A. 2010. Investigation of the Effect of Electrode Extension Distance on Microstructural and Mechanical Properties of Low Carbon Steel Welded with Submerged Arc Welding. Gazi University Journal of Science, 18 (3), 473480.

Kou, S. 2003. 'Welding Metallurgy', John Willey, USA 2nd edition.

Külahlı E. 1988. ''Kaynak Bilimi',, Oerlikon Yayını, Sayı-2.

Kuş, H., Altıparmak, D., BAŞAR, G. 2016. 'Sıcak Presleme Yöntemi ile Üretilmiş Uçucu Kül Takviyeli Bronz Matrisli Fren Balata Malzemelerinin Sürtünme-Așınma Özellikleri Üzerine Kolemanit Miktarının Etkisi', Politeknik Dergisi, 19 (4), 537-546.

Kütük S.T., KARA, C. 2018. ''Farklı Kür Koşullarının Kolemanit İkameli Betonların Dayanımina Etkisi', Journal of Investigations on Engineering \& Technology, 1 (2), 19-23.

Lehto, P., Remes, H., Saukkonen, T., Hänninen, H., Romanoff, J. 2014. "'Influence of Grain Size Distribution on The Hall-Petch Relationship of Welded Structural Steel',
Materials Science and Engineering: A Volume 592, 28-39.

Liu, M.Y., Shi, B., Wang, C., Ji, S.K., Cai, X., Song, H.W. 2003. "Normal Hall-Petch Behavior of Mild Steel with Submicron Grains", Materials Letters, vol.57, 27982802.

Melfi, T. 2010. 'New Codes Requirements for Calculating Heat İnput', Welding Journal, 61-63.

Morova, N., Terzi, S. 2015. "Evaluation of Colemanite Waste as Aggregate Hot Mix Asphalt Concrete", Süleyman Demirel Üniversitesi Fen Bilimleri Enstitüsü Dergisi 19/2, 8-15.

Nowacki, J., Rybicki, P. 2005. "The Influence of Welding Heat Input on Submerged Arc Welded Duplex Steel Joints Imperfections", Journal of Materials Processing Technology, Volumes 164-165, 1082-1088.

Ruşen A., Geveci A., Topkaya Y. 2012. "Minimization of Copper Losses to Slag in Matte Smelting by Colemanite Addition", The 17th International Symposium on Boron, Borides and Related Materials, Vol.14, 1112, 1702-1704.

Savaşkan T. 2009. Malzeme Bilgisi ve Muayenesi, Genişletilmiş 5.Baskı Trabzon.

Sivrikaya O., Arol A.İ. 2012. "The Bonding/Strengthening Mechanism of Colemanite Added Organic Binders in Iron Ore Pelletization', International Journal of Mineral Processing, vol.110-111, 90-100.

Sugözü, B., Buldum, B., Sugözü, İ. 2018. 'Üleksit ve Boraks İçeren Fren Sürtünme Malzemelerinin Tribolojik Özellikleri', Journal of Boron, 3 (2), 126131.

Zhao, M.C., Hanamura, T., Qiu, H., Nagai, K., Yang, K. 2006. 'Grain Growth And HallPetch Relation in Dual-Sized Ferrite/Cementite Steel with Nano-Sized Cementite Particles in a Heterogeneous and Dense Distribution", Scripta Materialia vol.54, 1193-1197. 